\title{
Bright Blue and Green
}

\section{Luminescence of $\mathrm{Sb}(\mathrm{III})$ in Double} Perovskite Cs2MlnCl6 ( $\mathrm{M}=\mathrm{Na}, \mathrm{K})$

\section{Matrices}

\section{Journal Article}

Author(s):

Noculak, Agnieszka; Morad, Viktoriia; McCall, Kyle M.; Yakunin, Sergii; Shynkarenko, Yevhen; Wörle, Michael; Kovalenko, Maksym V.

Publication date:

2020-06-23

\section{Permanent link:}

https://doi.org/10.3929/ethz-b-000425961

\section{Rights / license:}

Creative Commons Attribution-NonCommercial-NoDerivatives 4.0 International

\section{Originally published in:}

Chemistry of Materials 32(12), https://doi.org/10.1021/acs.chemmater.0c01004 


\title{
Bright Blue and Green Luminescence of $\mathrm{Sb}(\mathrm{III})$ in Double Perovskite $\mathrm{Cs}_{2} \mathrm{MInCl}_{6}(\mathrm{M}=\mathrm{Na}, \mathrm{K})$ Matrices
}

\author{
Agnieszka Noculak, ${ }^{\S}$ Viktoriia Morad, ${ }^{\S}$ Kyle M. McCall, Sergii Yakunin, Yevhen Shynkarenko, \\ Michael Wörle, and Maksym V. Kovalenko*
}

Cite This: Chem. Mater. 2020, 32, 5118-5124

Read Online

\section{ACCESS | Lill Metrics \& More | 回 Article Recommendations ｜（） Supporting Information}

ABSTRACT: The vast structural and compositional space of metal halides has recently become a major research focus for designing inexpensive and versatile light sources; in particular, for applications in displays, solid-state lighting, lasing, etc. Compounds with isolated $\mathrm{ns}^{2}$-metal halide centers often exhibit bright broadband emission that stems from self-trapped excitons (STEs). The $\mathrm{Sb}$ (III) halides are attractive STE emitters due to their low toxicity and oxidative stability; however, coupling these features with an appropriately robust, fully inorganic material containing $\mathrm{Sb}^{3+}$ in an octahedral halide environment has proven to be a challenge. Here, we investigate $\mathrm{Sb}^{3+}$ as a dopant in a

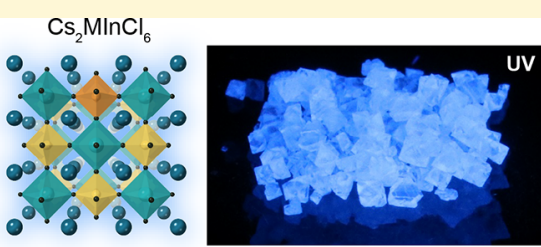

$\mathrm{Sb}(\mathrm{III})$ doping $\longrightarrow$ Bright broadband STE emission solution-grown metal halide double perovskite (DP) matrix, namely $\mathrm{Cs}_{2} \mathrm{MInCl}_{6}: x \mathrm{Sb}(\mathrm{M}=\mathrm{Na}, \mathrm{K}, x=0-100 \%) . \mathrm{Cs}_{2} \mathrm{KInCl}_{6}$ is found to crystallize in the tetragonal DP phase, unlike $\mathrm{Cs}_{2} \mathrm{NaInCl}_{6}$ that adopts the traditional cubic DP structure. This structural difference results in distinct emission colors, as $\mathrm{Cs}_{2} \mathrm{NaInCl}_{6}: x \mathrm{Sb}$ and $\mathrm{Cs}_{2} \mathrm{KInCl}_{6}: x \mathrm{Sb}$ compounds exhibit broadband blue and green emissions, respectively, with photoluminescence quantum yields (PLQYs) of up to 93\%. Spectroscopic and computational investigations confirm that this efficient emission originates from $\mathrm{Sb}$ (III)-hosted STEs. These fully inorganic DP compounds demonstrate that $\mathrm{Sb}$ (III) can be incorporated as a bright emissive center for stable lighting applications.

$\mathrm{L}$ ight-emitting $\mathrm{ns}^{2}$-metal halide-based materials have been the subject of continued interest over several decades, owing to the facile synthesis by wet and solid-state methods as well as their exceptional electronic and optical properties. The latter include narrowband and broadband emission for display technologies, ${ }^{1-4}$ lasing, ${ }^{5-8}$ quantum light sources, ${ }^{9}$ solid-state lighting, ${ }^{10}$ scintillators, ${ }^{11}$ remote thermography, ${ }_{12}^{12}$ and luminescent solar light converters and concentrators. ${ }^{13,14}$

The vast variety of luminescence characteristics arises from structural tunability. Metal halide polyhedral units as building blocks can form extended structures (e.g., $\mathrm{APbX}_{3}, \mathrm{~A}_{2} \mathrm{AgBiX}_{6}$, where $\mathrm{A}=$ monovalent cation, $\mathrm{X}=\mathrm{Cl}, \mathrm{Br}, \mathrm{I})$ with predominantly Wannier-Mott-type excitons, ${ }^{15-17}$ layered structures with both Wannier-Mott and Frenkel excitons, ${ }^{18,19}$ and fully isolated OD metal halides exhibiting characteristic broadband emission from self-trapped excitons (STEs) of Frenkel-type. ${ }^{20}$ For generating STE emission in the visible region, the most suitable $\mathrm{ns}^{2}$-metals include $\mathrm{Ge}(\mathrm{II}), \mathrm{Sn}$ (II), $\mathrm{Sb}(\mathrm{III})$, and $\mathrm{Te}(\mathrm{IV})$, whereas $\mathrm{Pb}(\mathrm{II})$ and $\mathrm{Bi}(\mathrm{III})$ systematically display higher energy emission, often in the UV region. ${ }^{21-23}$ In this work, we have concentrated our attention on the broad STE emission from $\mathrm{Sb}$ (III) due to its oxidative stability, in great contrast to the unstable oxidation states of $\mathrm{Ge}$ (II) and $\mathrm{Sn}(\mathrm{II})$. Organic-inorganic $\mathrm{Sb}$ (III) halide hybrids with various organic cations exhibit broadband and strongly Stokes-shifted emission in the yellow-red region with near-unity photoluminescence quantum yield (PLQY) at room temperature (RT). ${ }^{24-27}$ In contrast, the known fully inorganic $\mathrm{Sb}(\mathrm{III})$ compounds (e.g., $\left.\mathrm{Cs}_{3} \mathrm{Sb}_{2} \mathrm{X}_{9}, \mathrm{Cs}_{2} \mathrm{NaSbX}_{6}\right)^{28,29}$ are nonemissive at RT, although they are much more desirable due to their higher thermal stability. Therefore, to achieve an efficient RT STE of $\mathrm{Sb}^{3+}$, we adopt an alternative strategy, namely, doping $\mathrm{ns}^{2}$-metal ions into a suitable inorganic halide matrix. ${ }^{20,30}$ In this case, the doping level serves as a useful tuning knob for maximizing the emission intensity or preventing self-quenching at high concentrations. For example, the $\mathrm{Sb}^{3+}$ ions in $\mathrm{Cs}_{2} \mathrm{NaSbCl}_{6}$ fully quench each other at $\mathrm{RT},{ }^{29}$ requiring the use of diluted $\mathrm{Sb}^{3+}$ systems for RT emission. The most suitable fully inorganic matrix has to provide an $\mathrm{O}_{h}$ halide environment for $\mathrm{Sb}^{3+}$ and at the same time possess a wide optical band gap to prevent self-absorption. Doping on an isovalent host site is also advantageous, although examples of aliovalent $\mathrm{Sb}^{3+}$ doping are known. ${ }^{31}$ The matrix satisfying these requirements can be found among the halide elpasolites, also known as halide double perovskites (DPs). ${ }^{32}$ The structure of cubic elpasolites can be viewed as derived from a cubic perovskite structure $\mathrm{AM}^{\mathrm{II}} \mathrm{X}_{3}$ by the transmutation of a pair of $\mathrm{M}^{\mathrm{II}}$ sites into distinct $\mathrm{M}^{\mathrm{I}}$ and $\mathrm{M}^{\mathrm{III}}$ sites, resulting in an $\mathrm{A}_{2} \mathrm{M}^{\mathrm{I}} \mathrm{M}^{\mathrm{III}} \mathrm{X}_{6}$ stoichiometry. Although elpasolites are $3 \mathrm{D}$ structurally, in some compositions (where $\mathrm{M}^{\mathrm{I}}$ is an alkali halide metal), the orbital overlap

Received: March 6, 2020

Revised: $\quad$ May 22, 2020

Published: June 8, 2020 

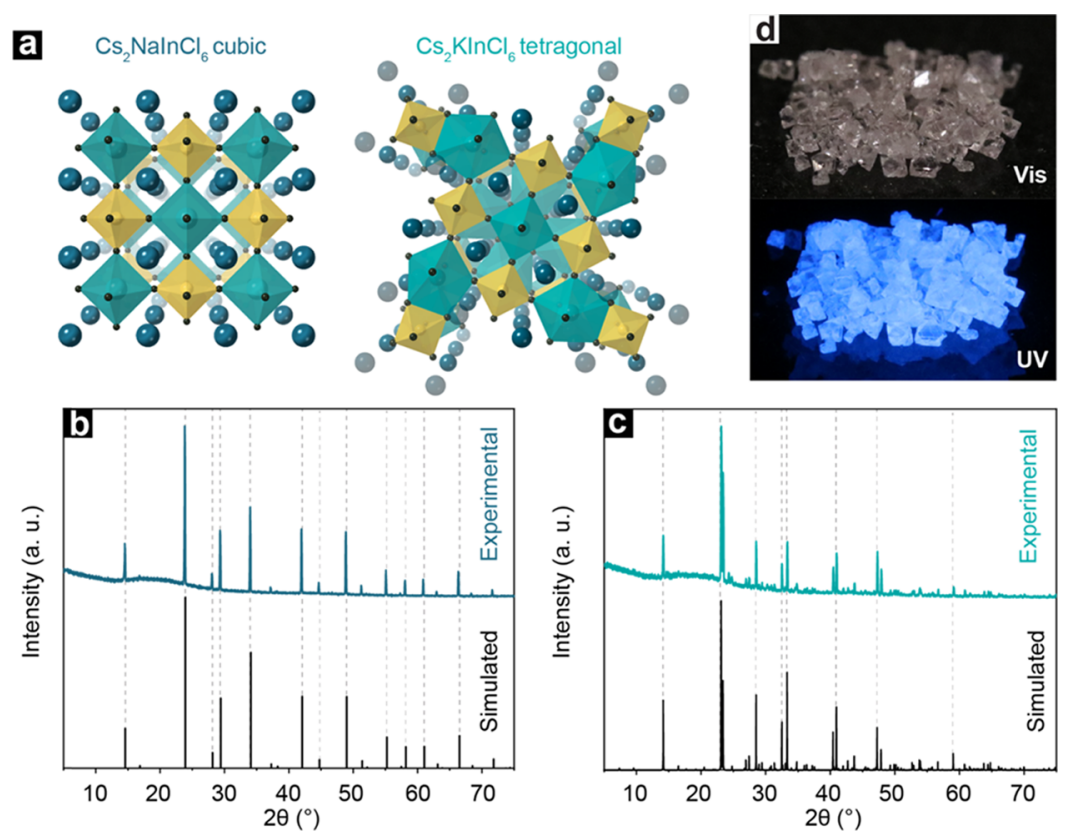

Figure 1. (a) Comparison of $\mathrm{Cs}_{2} \mathrm{NaInCl}_{6}$ and $\mathrm{Cs}_{2} \mathrm{KInCl}_{6}$ crystal structures, experimental and simulated XRD patterns for (b) $\mathrm{Cs}_{2} \mathrm{NaInCl}_{6}$ and (c) $\mathrm{Cs}_{2} \mathrm{KInCl}_{6}$. (d) Images of $\mathrm{Cs}_{2} \mathrm{NaInCl}_{6}: 1 \% \mathrm{Sb}$ crystals under visible light (Vis) and $365 \mathrm{~nm} \mathrm{UV}$ excitation.
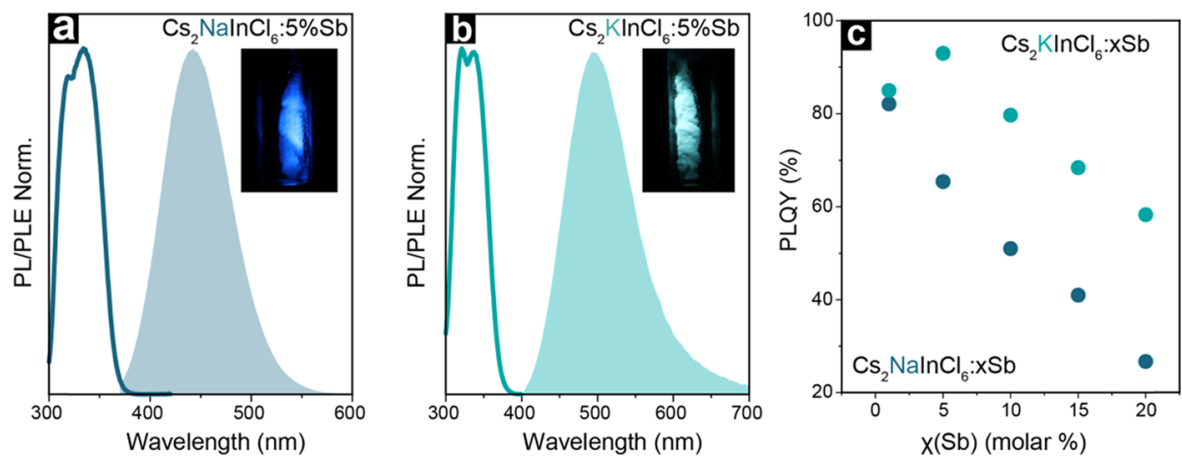

Figure 2. Typical PL (under $320 \mathrm{~nm}$ UV excitation) and PLE of (a) $\mathrm{Cs}_{2} \mathrm{NaInCl}_{6}: 5 \% \mathrm{Sb}$ and (b) $\mathrm{Cs}_{2} \mathrm{KInCl}_{6}: 5 \% \mathrm{Sb}$. (c) PLQY dependence on the concentration of the $\mathrm{Sb}^{3+}$ dopant.

between the nearest $\left[\mathrm{M}^{\mathrm{III}} \mathrm{Cl}_{6}\right]$ octahedra is broken by the adjacent $\left[\mathrm{M}^{\mathrm{I}} \mathrm{Cl}_{6}\right]$ octahedra, resulting in reduced electronic dimensionality. ${ }^{33}$ The emission of $\mathrm{Sb}^{3+}$ dopant in some bulk halide DP $\left(\mathrm{Cs}_{2} \mathrm{NaMX}_{6}\right.$, where $\mathrm{M}=\mathrm{Y}, \mathrm{Sc}$, La and $\left.\mathrm{X}=\mathrm{Cl}, \mathrm{Br}\right)$ was reported by Oomen et al. in the late 80 s. $^{34,35}$ These compounds exhibited emission centered in the range from 440 to $492 \mathrm{~nm}$, depending on the size of the space available for the $\mathrm{Sb}^{3+}$ ion. In this study, we have selected $\mathrm{In}^{3+}$ as a trivalent cation due to its oxidative and photostability, as well as the large optical band gap of the resulting DP. In addition to $\mathrm{Na}^{+}$, the larger $\mathrm{K}^{+}$was selected to fine-tune the $\mathrm{Sb}^{3+}$ emission. During the preparation of this manuscript, Zeng et al. also reported on $\mathrm{Sb}$-doped $\mathrm{Cs}_{2} \mathrm{NaInCl}_{6}$. ${ }^{36}$

When suitably small amounts of $\mathrm{Sb}^{3+}$ are doped into $\mathrm{Cs}_{2} \mathrm{NaInCl}_{6}$, the products retain the original structure, as confirmed by powder XRD (Figure S1). The peak positions shift linearly toward lower angles with increasing $\mathrm{Sb}^{3+}$ content, indicating a larger unit cell in agreement with Vegard's law (Figure S1b,c). This increase is the opposite of what is expected from the stated ionic radii of $\mathrm{Sb}^{3+}(76 \mathrm{pm})$, which is smaller than $\mathrm{In}^{3+}(80 \mathrm{pm}),{ }^{37}$ but is consistent with the larger lattice constant of $\mathrm{Cs}_{2} \mathrm{NaSbCl}_{6}(10.7780 \AA)$ relative to that of
$\mathrm{Cs}_{2} \mathrm{NaInCl}_{6}{ }^{38}$ This disparity can be ascribed to the bonddestabilizing effect of the $\mathrm{ns}^{2}$ lone pair, as described for $\mathrm{Bi}^{3+}$ by Shannon. ${ }^{37}$ To maintain an average cubic symmetry in $\mathrm{Cs}_{2} \mathrm{NaSbCl}_{6}$, the stereoactivity of the lone pair must lead to a highly dynamic distortion of the $\mathrm{SbCl}_{6}{ }^{3-}$ octahedra. ${ }^{29}$ The bond-length increase also confirms that $\mathrm{Sb}^{3+}$ substitutes into the $\mathrm{In}^{3+}$ position of $\mathrm{Cs}_{2} \mathrm{NaInCl}_{6}$, as any substitution of $\mathrm{Na}^{+}$by the much smaller $\mathrm{Sb}^{3+}$ ions would decrease the size of the unit cell. When $60 \%$ or more of $\mathrm{Sb}^{3+}$ is added during synthesis, weak peaks characteristic of the $\mathrm{Cs}_{3} \mathrm{Sb}_{2} \mathrm{Cl}_{9}$ impurity phase start to appear.

Contrary to the sodium-containing DP, the $\mathrm{Cs}_{2} \mathrm{KInCl}_{6}: x \mathrm{Sb}$ $(x=0,1,5,10,15,20$, and $40 \%)$ compounds could be prepared only as fine powders, which were not suitable for single-crystal XRD. Powder XRD patterns of $\mathrm{Cs}_{2} \mathrm{KInCl}_{6}$ show doubled peaks near the strong reflections of the $F m \overline{3} m$ cubic DP structure, indicating a structure of lower symmetry (Figure 1a,c). LeBail pattern matching using GSAS-II ${ }^{39}$ (Figure S2b) reveals that these compounds possess tetragonal symmetry, with the space group $I 4 / \mathrm{m}$ and unit cell parameters $a=b=$ 16.9732(2) $\AA$ and $c=10.9937(1) \AA$. This corresponds to a distorted DP structure (Figure S2a) due to the large size of the 
$\mathrm{K}^{+}$cation relative to the B-site cavity, as recently observed for the large cations $\mathrm{In}^{+}$and $\mathrm{Tl}^{+}$in the mixed-valent compounds $\mathrm{CsInCl}_{3}$ and $\mathrm{CsTlCl}_{3}{ }^{28,40}$ Rietveld refinement of the structure was attempted with the $\mathrm{CsInCl}_{3}$ structure as a starting point but did not converge due to the large unit cell of this supercell structure. The tetragonal $\mathrm{Cs}_{2} \mathrm{KInCl}_{6}$ structure is reported in this study for the first time. In theoretical studies, $\mathrm{Cs}_{2} \mathrm{KInCl}_{6}$ is usually assumed to adopt a cubic structure; however, this has been not experimentally demonstrated. ${ }^{33}$ Previously, only the monoclinic phase of $\mathrm{Cs}_{2} \mathrm{KInCl}_{6}$, isostructural to $\mathrm{Cs}_{2} \mathrm{KBiCl}_{6}$, was reported. $^{41,42}$

Extended exposure of $\mathrm{Cs}_{2} \mathrm{KInCl}_{6}: x \mathrm{Sb}$ to the acidic environment results in the incorporation of water molecules and the presence of the impurity phase $\mathrm{Cs}_{2} \mathrm{InCl}_{5}: x \mathrm{Sb} \cdot \mathrm{H}_{2} \mathrm{O}$ (Figure S2c). This complicates the interpretation of the powder XRD, as there is no clear trend in the lattice parameters with increasing $\mathrm{Sb}^{3+}$ content. This phase conversion also alters the optical properties as the maximum of the emission shifts toward longer wavelengths, while the maximum of the excitation band remains unchanged (Figure S2d,e). $\mathrm{Cs}_{2} \mathrm{NaInCl}_{6}: x \mathrm{Sb}$ samples exhibited no degradation upon storage in air for a few months, whereas with $\mathrm{Cs}_{2} \mathrm{KInCl}_{6}: x \mathrm{Sb}$, yellow-luminescent grains started to appear after a few weeks in air, indicating that the tetragonal structure may be metastable (Figure S3). Similar instability was observed for isostructural $\mathrm{CsInCl}_{3}{ }^{28}$.

Sb-doped $\mathrm{Cs}_{2} \mathrm{NaInCl}_{6}$ and $\mathrm{Cs}_{2} \mathrm{KInCl}_{6}$ samples exhibit broadband blue and green $\mathrm{PL}$ (Figure 2a,b), respectively, while the undoped $\mathrm{Cs}_{2} \mathrm{NaInCl}_{6}$ and $\mathrm{Cs}_{2} \mathrm{KInCl}_{6}$ compounds exhibited no visible PL at RT (Figure S4). This is in contrast to the study of Zeng et al., ${ }^{36}$ who reported a PL band with a maximum at $445 \mathrm{~nm}$ even for undoped structures. Sb-doped compounds also exhibit new bands in the absorption spectra corresponding to $\mathrm{Sb}$ states within the band gap of the $\mathrm{Cs}_{2} \mathrm{MInCl}_{6}$ matrix (Figure S5). As the PL intensities are low for the samples with high $\mathrm{Sb}^{3+}$ content due to self-quenching, we mainly analyzed the samples with $\mathrm{Sb}^{3+}$ concentration below $20 \%$. For $\mathrm{ns}^{2}$ ions such as $\mathrm{Sb}^{3+}$, the ground state is denoted by the ${ }^{1} S_{0}$ atomic term, whereas the excited state (sp) splits into four energy levels, namely, ${ }^{1} \mathrm{P}_{1},{ }^{3} \mathrm{P}_{0},{ }^{3} \mathrm{P}_{1}$, and ${ }^{3} \mathrm{P}_{2}$. The ${ }^{1} \mathrm{~S}_{0}-{ }^{1} \mathrm{P}_{1}$ transition is allowed, and the ${ }^{1} S_{0}-{ }^{3} P_{1}$ transition is partially allowed due to spin-orbit coupling for heavy atoms, while the ${ }^{1} \mathrm{~S}_{0}-{ }^{3} \mathrm{P}_{2}$ and ${ }^{1} \mathrm{~S}_{0}-{ }^{3} \mathrm{P}_{0}$ transitions are totally forbidden at the electric dipole transition level. The characteristic excitation band (commonly denoted as the A-band) with two maxima at 320 and $335 \mathrm{~nm}$ can be assigned to be the ${ }^{1} \mathrm{~S}_{0}-{ }^{3} \mathrm{P}_{1}$ transition of $\mathrm{Sb}^{3+}$ (PLE maps are presented in Figure S6a,b). The split in the PLE band has been ascribed to a dynamic Jahn-Teller distortion in the excited state. ${ }^{34}$ The PL emission situated in the 380-700 nm range (with a maximum near $445 \mathrm{~nm}$ for $\mathrm{Cs}_{2} \mathrm{NaInCl}_{6}: 5 \% \mathrm{Sb}$ and $495 \mathrm{~nm}$ for $\mathrm{Cs}_{2} \mathrm{KInCl}_{6}: 5 \% \mathrm{Sb}$ ) can be ascribed to the ${ }^{3} \mathrm{P}_{1}-{ }^{1} \mathrm{~S}_{0}$ transition, similar to the case of $\mathrm{Cs}_{2} \mathrm{NaMCl}_{6}(\mathrm{M}=\mathrm{Sc}, \mathrm{Y}, \mathrm{La})$ matrices. ${ }^{34}$ The Stokes shift of $\mathrm{Sb}^{3+}$ luminescence, defined as the energy difference between the maximum of the excitation and emission bands, is equal to 110 and $160 \mathrm{~nm}$ for $\mathrm{Cs}_{2} \mathrm{NaInCl}_{6}: 5 \% \mathrm{Sb}$ and $\mathrm{Cs}_{2} \mathrm{KInCl}_{6}: 5 \% \mathrm{Sb}$, respectively. The shape and maxima of the PL excitation (PLE) and PL spectra remain the same for different amounts of $\mathrm{Sb}^{3+}$ ions in the crystal structure (Figure S7a,b). The only exception is in the PL spectrum of $\mathrm{Cs}_{2} \mathrm{KInCl}_{6}: 1 \% \mathrm{Sb}$, where a shoulder was observed at low energy, which seems to originate from the $\mathrm{Cs}_{2} \mathrm{InCl}_{5} \cdot \mathrm{H}_{2} \mathrm{O}: 1 \% \mathrm{Sb}$ impurity.
As demonstrated in Figure 2c, the amount of $\mathrm{Sb}^{3+}$ dopant strongly influences PLQY. The highest PLQYs were obtained for the $\mathrm{Cs}_{2} \mathrm{NaInCl}_{6}: 1 \% \mathrm{Sb}$ and $\mathrm{Cs}_{2} \mathrm{KInCl}_{6}: 5 \% \mathrm{Sb}$ structures $\left(\lambda_{\text {exc }}\right.$ $=320 \mathrm{~nm}$ ) and were equal to 82 and $93 \%$, respectively. A further increase of the doping level caused the self-quenching effect. Figure 3a shows the time-resolved PL decay curves of
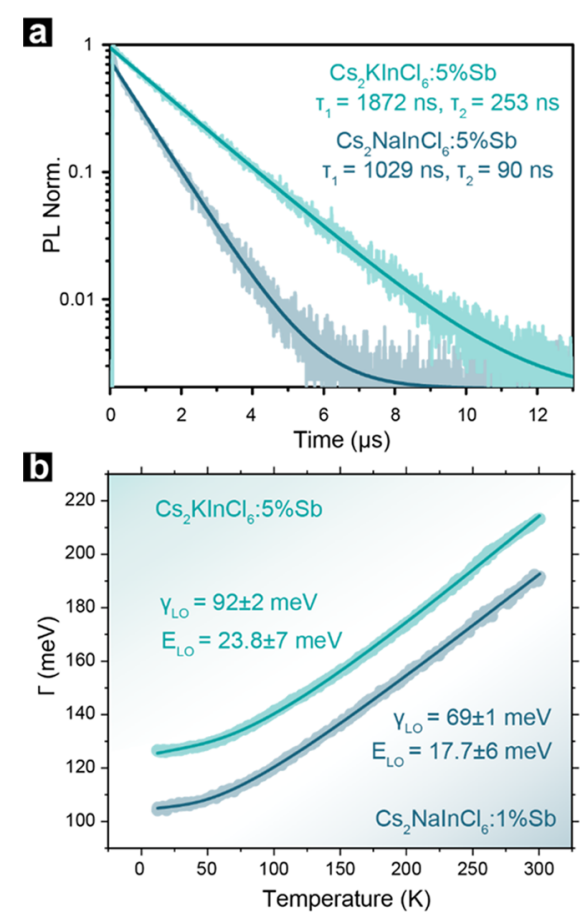

Figure 3. (a) Time-resolved PL decay curves of $\mathrm{Cs}_{2} \mathrm{NaInCl}_{6}: 5 \% \mathrm{Sb}$ and $\mathrm{Cs}_{2} \mathrm{KInCl}_{6}: 5 \% \mathrm{Sb}$ measured at 445 and $495 \mathrm{~nm}$, respectively, at RT $\left(\lambda_{\text {exc }}-320 \mathrm{~nm}\right)$ and the corresponding time constants of the biexponential fit. (b) Experimental dependence of the PL peak broadening with temperature for $\mathrm{Cs}_{2} \mathrm{NaInCl}_{6}: 1 \% \mathrm{Sb}$ and $\mathrm{Cs}_{2} \mathrm{KInCl}_{6}: 5 \% \mathrm{Sb}$. The experimental data are fitted with a model (solid line), from which the electron-phonon coupling strength $\left(\gamma_{\mathrm{LO}}\right)$ and optical phonon energies $\left(E_{\mathrm{LO}}\right)$ are obtained.

$\mathrm{Cs}_{2} \mathrm{NaInCl}_{6}: 5 \% \mathrm{Sb}$ and $\mathrm{Cs}_{2} \mathrm{KInCl}_{6}: 5 \% \mathrm{Sb}$ measured at 445 and $495 \mathrm{~nm}$, respectively, at RT $\left(\lambda_{\text {exc }}-320 \mathrm{~nm}\right)$. The curves at all doping levels up to $20 \%$ can be fitted biexponentially (see Table S6 and Figure S7c). For $\mathrm{Cs}_{2} \mathrm{NaInCl}_{6}: 1 \% \mathrm{Sb}$, we obtained a short-lived PL lifetime of 96 ns with a percentage of $12 \%$ and a long-lived PL lifetime of 1029 ns with a percentage of $88 \%$. As the concentration increases, we can observe a gradual decrease of both short- and long-lived PL lifetimes, along with a higher proportion of the faster component (Table S6). According to Reisfeld et al., ${ }^{43}$ two recombination routes are possible for the excited state in $\mathrm{Sb}^{3+}:{ }^{3} \mathrm{P}_{0}-{ }^{1} \mathrm{~S}_{0}$ recombination with a faster decay rate and ${ }^{3} \mathrm{P}_{1}-{ }^{1} \mathrm{~S}_{0}$ with a slower decay rate. Similar behavior is observed for $\mathrm{Cs}_{2} \mathrm{KInCl}_{6}: x \mathrm{Sb}$ samples (see Table S6 and Figure S7d).

To better understand the influence of exciton-phonon coupling, we have analyzed the PL line broadening with temperature. This has been done by first extracting the PL linewidth by fitting the peak with exponentially modified Gaussian, and then plotting the obtained full width at half maximum against temperature. The resulting data can be fit with the Rudin model $^{44}$

$$
\Gamma(T)=\Gamma_{0}+\Gamma_{\mathrm{ac}}+\Gamma_{\mathrm{LO}}+\Gamma_{\mathrm{imp}}
$$




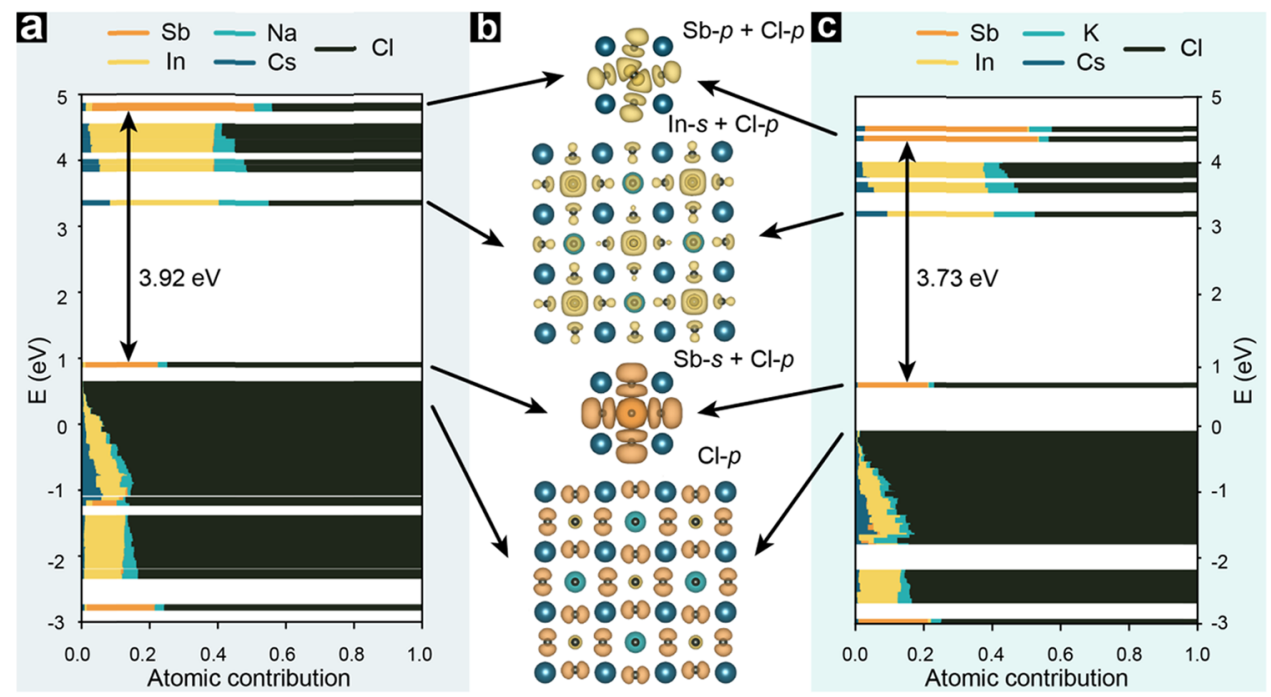

Figure 4. (a) Electronic structure of $\mathrm{Cs}_{2} \mathrm{NaInCl}_{6}$ with one $\mathrm{Sb}^{3+}$ ion at a $\Gamma$ point in a $2 \times 2 \times 2$ supercell, computed at a DFT/PBE level. (b) Projected atomic HOMO (orange) and LUMO (yellow) of the host material and $\mathrm{SbCl}_{6}$ centers; the HOMO and the LUMO of the host consist of Cl-p and In-s + Cl-p states, respectively, whereas the HOMO and the LUMO of the dopant comprise Sb-s + Cl-p and Sb-p + Cl-p, respectively. (c) Electronic structure of $\mathrm{Cs}_{2} \mathrm{KInCl}_{6}$ with one $\mathrm{Sb}^{3+}$ ion at a $\Gamma$ point in a $1 \times 1 \times 2$ supercell, computed at the DFT/PBE level.

The $\Gamma_{0}$ is a temperature-independent inhomogeneous broadening, which is related to scattering due to disorder and imperfections. The second and third terms represent homogeneous broadening, resulting from scattering from acoustic and optical phonons. The last term accounts for the scattering of ionized impurities and does not contribute in the case of $\mathrm{Cs}_{2} \mathrm{MInCl}_{6}: x \mathrm{Sb}$. Electron-phonon coupling is proportional to the occupation of the phonon energy states and can be described by Bose-Einstein distribution

$$
\Gamma_{\mathrm{LO}}=\gamma_{\mathrm{LO}} \frac{1}{\mathrm{e}^{E_{\mathrm{LO}} / k_{\mathrm{B}} T}-1}
$$

where the constant $\gamma_{\mathrm{LO}}$ represents the exciton-optical phonon coupling strength and $E_{\mathrm{LO}}$ is the energy of the optical phonon involved in homogeneous PL linewidth broadening. For the acoustic phonons, the dependence is linear: $\Gamma_{\mathrm{ac}}=\gamma_{\mathrm{ac}} T$. For the fitting, we have taken into account only the first three terms. Figure S8 shows the evolution of the PL line shape with temperature. Figure $3 \mathrm{~b}$ summarizes the results obtained from fitting of PL and lists fit values related to the optical phonon coupling strength and energy. In the case of $\mathrm{Cs}_{2} \mathrm{NaInCl}_{6}: x \mathrm{Sb}$, the energies of phonons involved in $\mathrm{PL}$ broadening are lower $(17.7 \pm 6 \mathrm{meV})$ than those for $\mathrm{Cs}_{2} \mathrm{KInCl}_{6}: x \mathrm{Sb}(23.8 \pm 7$ $\mathrm{meV})$. The same trend is observed in the coupling constant values $(69 \pm 1$ vs $92 \pm 2 \mathrm{meV})$. Interestingly, the $17.7 \mathrm{meV}$ phonon energy for $\mathrm{Cs}_{2} \mathrm{NaInCl}_{6}: x \mathrm{Sb}$ falls in the region of the phonon band structure with states originating mainly from the $\mathrm{Na}-\mathrm{Cl}$ bonds. The inhomogeneous broadening is also higher in the case of $\mathrm{Cs}_{2} \mathrm{KInCl}_{6}: x \mathrm{Sb}$. This analysis reflects the difference in the crystal structure, where the lower symmetry of the potassium analogue influences the optical properties of the impurity ion $\mathrm{Sb}^{3+}$.

DFT calculations were utilized to analyze the electronic structure of $\mathrm{Cs}_{2} \mathrm{MInCl}_{6}: x \mathrm{Sb}$ and rationalize the STE-derived optical properties. The electronic density of states (DOS) and projected molecular orbitals have been calculated with the $\mathrm{CP} 2 \mathrm{~K}$ package at the $\mathrm{DFT} / \mathrm{PBE}$ level of theory using the model system comprising a $\mathrm{Cs}_{2} \mathrm{MInCl}_{6} 2 \times 2 \times 2$ supercell with one $\mathrm{Sb}$ atom per supercell (about $3 \mathrm{~mol} \%$ ). It has been previously discussed that $\mathrm{Cs}_{2} \mathrm{MInCl}_{6}$ possesses a direct but parity-forbidden band gap $(2.73 \mathrm{eV})$ at the $\Gamma$-point. ${ }^{33}$ This results in a very low oscillator strength of the edge-to-edge transition, rendering undoped $\mathrm{Cs}_{2} \mathrm{MInCl}_{6}$ weakly absorbing and nonluminescent. In $\mathrm{Cs}_{2} \mathrm{MInCl}_{6}$, the highest occupied molecular orbital (HOMO) and the lowest unoccupied molecular orbital (LUMO) comprise Cl-p states and In-s + Cl-p states, respectively. The electronic structure is not well dispersed and electronic bands are flat (see the Supporting Information for computational details). In a recent study by Zeng et al., STE emission from Sb-doped $\mathrm{Cs}_{2} \mathrm{NaInCl}_{6}$ was explored with DFT and rationalized as an effect of breaking the parity-forbidden transition and modulation of the density of states due to $\mathrm{Sb}^{3+}$ doping. ${ }^{36}$

The analysis of the DOS of the Sb-doped $\mathrm{Cs}_{2} \mathrm{NaInCl}_{6}$ with a cubic structure shows that the $\mathrm{SbCl}_{6} \mathrm{HOMO}$ appears above the host valence band while the $\mathrm{SbCl}_{6} \mathrm{LUMO}$ appears in a gap deep in the host conduction band (Figures $4 a$ and S9). The oscillator strength of the $\mathrm{SbCl}_{6} \mathrm{HOMO}-\mathrm{LUMO}$ transition is much higher than those of the matrix, and therefore both optical excitation and emission are occurring between $\mathrm{SbCl}_{6}$ states. The $\mathrm{SbCl}_{6} \mathrm{HOMO}$ has Sb-s and Cl-p character, whereas the LUMO consists of Sb-p and Cl-p orbitals. This can also be confirmed by calculating the $\mathrm{SbCl}_{6} \mathrm{HOMO} \mathrm{HUMO}$ difference, $3.92 \mathrm{eV}$, which is close to the experimental PLE peak at $12 \mathrm{~K}$ of $3.75 \mathrm{eV}$ (Figure S10). For Sb-doped $\mathrm{Cs}_{2} \mathrm{KInCl}_{6}$, which has a tetragonal structure, the predicted $\mathrm{SbCl}_{6} \mathrm{HOMO}-$ LUMO gap is lower $(3.73 \mathrm{eV})$ and better agrees with the experiment (Figure 4c). The calculations confirm that the observed luminescence mechanism does not involve states from the DP host, but both HOMO and LUMO are localized on the dopant sites, namely, $\mathrm{SbCl}_{6}$ octahedra.

In summary, we have designed and synthesized $\mathrm{Cs}_{2} \mathrm{MInCl}_{6}: x \mathrm{Sb}(\mathrm{M}=\mathrm{Na}, \mathrm{K})$ phosphors with blue and green emission and PLQYs of 82 and 93\%, respectively. Experimental and computational studies reveal that the optical properties originate from STEs localized on $\mathrm{SbCl}_{6}$ centers. We demonstrate that the emission maximum of the $\mathrm{Sb}^{3+}$ dopant can be tuned not only by exchanging the $\mathrm{M}^{\mathrm{III}}$ cation, but also 
the $\mathrm{M}^{\mathrm{I}}$ cation. Replacement of the $\mathrm{Na}^{+}$cation by the larger $\mathrm{K}^{+}$ cation causes structural changes due to the size of the cation, resulting in a shift from cubic to tetragonal symmetry. This change is reflected in the increase of the Stokes shift and electron-phonon coupling. We anticipate that such fully inorganic, thermally robust, and bright emitters will find applications in solid-state lighting as well as emerging niches such as remote thermography, scintillation, neutron detection, cathodoluminescence, etc.

\section{EXPERIMENTAL SECTION}

The list of chemicals is available in the Supporting Information.

Synthesis of $\mathrm{Cs}_{2} \mathrm{NaInCl}_{6}: x \mathrm{Sb}$ Powder. $\mathrm{Cs}_{2} \mathrm{NaInCl}_{6}: x \mathrm{Sb}$ was synthesized from stoichiometric quantities of $\mathrm{CsCl}, \mathrm{NaCl}, \mathrm{InAc}_{3}$ and $\mathrm{SbAc}_{3}$ precursors in $\mathrm{HCl}$. Briefly, $0.6 \mathrm{mmol}$ of $\mathrm{CsCl}$ and $0.3 \mathrm{mmol}$ of $\mathrm{NaCl}$ powders were dissolved in $4 \mathrm{~mL}$ of $\mathrm{HCl}$ under stirring in an 8 $\mathrm{mL}$ vial at $100{ }^{\circ} \mathrm{C}$. Separately, stoichiometric amounts of $\mathrm{SbAc}_{3}$ and $\mathrm{InAc}_{3}$ were dissolved in $1 \mathrm{~mL}$ of $\mathrm{HCl}$ and heated at $100{ }^{\circ} \mathrm{C}$. When all of the precursors were dissolved, both solutions were mixed together and immediate precipitation of the colorless product was observed. The as-obtained product was separated by filtration and dried in air at $50{ }^{\circ} \mathrm{C}$ for $6 \mathrm{~h}$. Reaction yield: $79 \%$.

Synthesis of $\mathrm{Cs}_{2} \mathrm{KInCl}_{6}: x \mathrm{Sb}$ Powder. $\mathrm{Cs}_{2} \mathrm{KInCl}_{6}: x \mathrm{Sb}$ was synthesized in the same way as $\mathrm{Cs}_{2} \mathrm{NaInCl}_{6}: x \mathrm{Sb}$, with the only difference being that $0.6 \mathrm{mmol}$ of $\mathrm{CsCl}$ and $0.15 \mathrm{mmol}$ of $\mathrm{K}_{2} \mathrm{CO}_{3}$ were dissolved in $1 \mathrm{~mL}$ of $\mathrm{HCl}$ at $100{ }^{\circ} \mathrm{C}$, and stoichiometric amounts of $\mathrm{SbAc}_{3}$ and $\mathrm{InAc}_{3}$ were dissolved in $1 \mathrm{~mL}$ of $\mathrm{HCl}$ in another vial. When all of the precursors were dissolved, both solutions were mixed together and immediate precipitation of the fine powder was observed. The resulting material was collected and filtered immediately after formation. Leaving the product in the mother solution longer results in the formation of a stable $\mathrm{Cs}_{2} \mathrm{InCl}_{5} x \mathrm{H}_{2} \mathrm{O}: x \mathrm{Sb}$ phase. Reaction yield: $59 \%$.

Synthesis of $\mathrm{Cs}_{2} \mathrm{NaInCl}_{6}: \mathrm{xSb}$ Single Crystals. $\mathrm{Cs}_{2} \mathrm{NaInCl}_{6}: x \mathrm{Sb}$ was synthesized from stoichiometric quantities of $\mathrm{CsCl}, \mathrm{NaCl}, \mathrm{InAc}_{3}$, and $\mathrm{SbAc}_{3}$ precursors in $\mathrm{HCl}$. Briefly, $0.6 \mathrm{mmol}$ of $\mathrm{CsCl}, 0.3 \mathrm{mmol}$ of $\mathrm{NaCl}$, and stoichiometric amounts of $\mathrm{SbAc}_{3}$ and $\mathrm{InAc}_{3}$ were dissolved in $6 \mathrm{~mL}$ of $\mathrm{HCl}$ under stirring in a $12 \mathrm{~mL}$ vial and heated at $100{ }^{\circ} \mathrm{C}$. When all of the precursors were dissolved, the temperature was decreased to room temperature and small crystals grew overnight. To ensure the total removal of surface-adsorbed ions, the tiny crystals were rinsed with fresh $\mathrm{HCl}$. The crystalline product was dried in the air at $50{ }^{\circ} \mathrm{C}$ for $6 \mathrm{~h}$.

Characterization. Powder XRD patterns were collected in transmission mode (Debye-Scherrer Geometry) with an STADI P diffractometer (STOE \& $\mathrm{Cie} \mathrm{GmbH}$ ) equipped with a curved $\mathrm{Ge}(111)$ monochromator $\left(\mathrm{Cu} \mathrm{K} \alpha_{1}=1.54056 \AA\right)$ and a silicon strip MYTHEN $1 \mathrm{~K}$ detector (Fa. DECTRIS). For the measurement, the ground powder was placed between adhesive tape, with the exception of $\mathrm{Cs}_{2} \mathrm{KInCl}_{6}$, which was measured in a Mark-tube capillary of $0.1 \mathrm{~mm}$ diameter. Single-crystal XRD measurements were conducted on a Bruker Smart Platform diffractometer equipped with an Apex I CCD detector and a molybdenum (Mo K $\alpha=0.71073 \AA$ ) sealed tube as an $\mathrm{X}$-ray source. Crystals were tip-mounted on a micromount using paraffin oil. The data were processed with Oxford Diffraction CrysAlis Pro software, and structure solution and refinement were performed with SHELXS and SHELXL respectively, embedded in the Olex2 package. $^{45,46}$ For material composition analysis, we used XRF spectroscopy. The Amptek Complete XRF Experimenter's Kit was used with an $\mathrm{Ag}$ Mini-X tube as a source, X-123 as a detector, PX-5 as an amplifier and digitizer, and XRS-FP2 quantitative analysis software to recalculate the measured XRF peak intensity into the material composition. The multiple standards calibration method was used with reference samples of known composition.

A Fluorolog iHR 320 Horiba Jobin Yvon spectrofluorometer equipped with a PMT detector was used to acquire steady-state photoluminescence (PL) and PL excitation (PLE) spectra from solutions. Absolute PL quantum yield (QY) of solutions were measured with a Quantaurus-QY Absolute PL quantum yield spectrometer from Hamamatsu. Time-resolved photoluminescence (TR-PL) measurements were performed using a time-correlated single-photon counting (TCSPC) setup, equipped with an SPC-130EM counting module (Becker \& Hickl GmbH) and an IDQID-10020-ULN avalanche photodiode (Quantique) for recording the decay traces.

Computational Details. Calculations were carried out at the density functional theory level as implemented in the cp2k quantum chemistry code. A doubled $2 \times 2 \times 2$ unit cell containing 320 atoms with one $\mathrm{Sb}$ atom on an In position for cubic $\mathrm{Cs}_{2} \mathrm{NaInCl}_{6}: x \mathrm{Sb}$ and a 1 $\times 1 \times 2$ unit cell containing 200 atoms with one $\mathrm{Sb}$ atom on an In position for tetragonal $\mathrm{Cs}_{2} \mathrm{KInCl}_{6}: x \mathrm{Sb}$ was constructed. A mixed plane-wave and Gaussian basis set approach was used to describe the wave function and electronic density, respectively. The kinetic energy cutoff of the plane-wave basis was set to $400 \mathrm{Ry}$, while a double- $\zeta$ basis set plus polarization functions was employed to describe the molecular orbitals. The density of states (DOS) and emission and excitation energies were calculated using the Perdew-BurkeErnzerhof (PBE) exchange-correlation functional. Scalar relativistic effects have been accounted for using effective core potential functions in the basis set. Spin-orbit coupling effects were not included. Calculations with lattice relaxation for the ground state geometry optimization were performed to account for statistical disorder in the experimental crystal structures. Unit cell parameters were taken from experimental data and not relaxed, whereas atomic coordinates were optimized until the force reached $0.023 \mathrm{eV} / \AA$.

For the band structure calculations, the Vienna ab initio simulations package (VASP) was used. The projector augmented wave (PAW) potentials for atoms were used. ${ }^{47,48}$ For the generalized gradient approximation (GGA), the Perdew-Burke-Ernzerhof exchange-correlation functional (PBE) was used. ${ }^{49}$ A single cell comprising 320 atoms with a kinetic energy cutoff of $520 \mathrm{eV}$ and automatic $\gamma$-centered mesh of $1 \times 1 \times 1 k$-points were used for geometry optimization. Ionic minimization was performed until all forces on atoms were smaller than $0.001 \mathrm{eV} / \AA$. A mixture of the blocked Davidson iteration scheme and the subsequent residual minimization scheme-direct inversion in the iterative subspace (RMM-DIIS) algorithm was used for electronic optimization. Spinorbit coupling (SOC) was not taken into account due to the known self-interaction error that increases the valence band maximum. ${ }^{50}$ The band structure was calculated along a high-symmetry $k$-point path according to Bradley and Cracknell. ${ }^{31}$

\section{ASSOCIATED CONTENT}

\section{Supporting Information}

The Supporting Information is available free of charge at https://pubs.acs.org/doi/10.1021/acs.chemmater.0c01004.

\section{Crystallographic data for $\mathrm{Cs}_{2} \mathrm{NaInCl}_{6}$ (CIF)}

Crystal data and structure refinement for $\mathrm{Cs}_{2} \mathrm{NaInCl}_{6}$; anisotropic displacement parameters; $\mathrm{Cs}_{2} \mathrm{KInCl}_{6}$ crystal structure; XRF analysis of $\mathrm{Sb}^{3+}$ concentration in $\mathrm{Cs}_{2} \mathrm{NaInCl}_{6}$ and $\mathrm{Cs}_{2} \mathrm{KInCl}_{6}$; PL spectra of doped and undoped samples; PL and PLE spectra measured on powdered crystals; PLE spectra of $\mathrm{Cs}_{2} \mathrm{NaInCl}_{6}: 1 \% \mathrm{Sb}$ at $12 \mathrm{~K}$ and at $300 \mathrm{~K}(\mathrm{PDF})$

\section{AUTHOR INFORMATION}

\section{Corresponding Author}

Maksym V. Kovalenko - Laboratory of Inorganic Chemistry, Department of Chemistry and Applied Bioscience, ETH Zürich, CH-8093 Zürich, Switzerland; Laboratory for Thin Films and Photovoltaics, Empa-Swiss Federal Laboratories for Materials Science and Technology, CH-8600 Dübendorf, Switzerland; ○ orcid.org/0000-0002-6396-8938; Email: mvkovalenko@ ethz.ch 


\section{Authors}

Agnieszka Noculak - Laboratory of Inorganic Chemistry, Department of Chemistry and Applied Bioscience, ETH Zürich, CH-8093 Zürich, Switzerland; Laboratory for Thin Films and Photovoltaics, Empa-Swiss Federal Laboratories for Materials Science and Technology, CH-8600 Dübendorf, Switzerland

Viktoriia Morad - Laboratory of Inorganic Chemistry, Department of Chemistry and Applied Bioscience, ETH Zürich, CH-8093 Zürich, Switzerland; Laboratory for Thin Films and Photovoltaics, Empa-Swiss Federal Laboratories for Materials Science and Technology, CH-8600 Dübendorf, Switzerland

Kyle M. McCall - Laboratory of Inorganic Chemistry, Department of Chemistry and Applied Bioscience, ETH Zürich, CH-8093 Zürich, Switzerland; Laboratory for Thin Films and Photovoltaics, Empa-Swiss Federal Laboratories for Materials Science and Technology, CH-8600 Dübendorf, Switzerland

Sergii Yakunin - Laboratory of Inorganic Chemistry, Department of Chemistry and Applied Bioscience, ETH Zürich, CH-8093 Zürich, Switzerland; Laboratory for Thin Films and Photovoltaics, Empa-Swiss Federal Laboratories for Materials Science and Technology, CH-8600 Dübendorf, Switzerland; () orcid.org/0000-0002-6409-0565

Yevhen Shynkarenko - Laboratory of Inorganic Chemistry, Department of Chemistry and Applied Bioscience, ETH Zürich, CH-8093 Zürich, Switzerland; Laboratory for Thin Films and Photovoltaics, Empa-Swiss Federal Laboratories for Materials Science and Technology, CH-8600 Dübendorf, Switzerland; (1) orcid.org/0000-0002-1587-1752

Michael Wörle - Laboratory of Inorganic Chemistry, Department of Chemistry and Applied Bioscience, ETH Zürich, CH-8093 Zürich, Switzerland

Complete contact information is available at:

https://pubs.acs.org/10.1021/acs.chemmater.0c01004

\section{Author Contributions \\ ${ }^{\S}$ A.N. and V.M. contributed equally.}

\section{Notes}

The authors declare no competing financial interest.

\section{ACKNOWLEDGMENTS}

This work was financial supported by the European Union through Horizon 2020 (ERC Consolidator Grant SCALEHALO, grant agreement no. [819740]) and by ETH Zurich $($ ETH + Project SynMatLab). A.N. acknowledges partial financial support from the EMPAPOSTDOCS-II program, which received funding from the European Union's Horizon 2020 Research and Innovation Program under the Marie Skłodowska-Curie grant agreement number 754364. The authors would like to acknowledge Kostiantyn Sakhatskyi for the X-ray fluorescence measurements, as well as Bogdan Benin and Dr Simon Boehme for fruitful discussions.

\section{REFERENCES}

(1) Yoon, H. C.; Lee, H.; Kang, H.; Oh, J. H.; Do, Y. R. Highly Efficient Wide-Color-Gamut QD-Emissive LCDs Using Red and Green Perovskite Core/Shell QDs. J. Mater. Chem. C 2018, 6, 1302313033.

(2) Ko, Y. H.; Jalalah, M.; Lee, S. J.; Park, J. G. Super Ultra-High Resolution Liquid-Crystal-Display Using Perovskite Quantum-Dot Functional Color Filters. Sci. Rep. 2018, 8, No. 12881.

(3) Chiba, T.; Hayashi, Y.; Ebe, H.; Hoshi, K.; Sato, J.; Sato, S.; Pu, Y. J.; Ohisa, S.; Kido, J. Anion-Exchange Red Perovskite Quantum
Dots with Ammonium Iodine Salts for Highly Efficient Light-Emitting Devices. Nat. Photonics 2018, 12, 681-687.

(4) Lin, K. B.; Xing, J.; Quan, L. N.; de Arquer, F. P. G.; Gong, X. W.; Lu, J. X.; Xie, L. Q.; Zhao, W. J.; Zhang, D.; Yan, C. Z.; Li, W. Q.; Liu, X. Y.; Lu, Y.; Kirman, J.; Sargent, E. H.; Xiong, Q. H.; Wei, Z. H. Perovskite Light-Emitting Diodes with External Quantum Efficiency Exceeding 20\%. Nature 2018, 562, 245-248.

(5) Yakunin, S.; Protesescu, L.; Krieg, F.; Bodnarchuk, M. I.; Nedelcu, G.; Humer, M.; De Luca, G.; Fiebig, M.; Heiss, W.; Kovalenko, M. V. Low-Threshold Amplified Spontaneous Emission and Lasing from Colloidal Nanocrystals of Caesium Lead Halide Perovskites. Nat. Commun. 2015, 6, No. 8056.

(6) Tan, Z. K.; Moghaddam, R. S.; Lai, M. L.; Docampo, P.; Higler, R.; Deschler, F.; Price, M.; Sadhanala, A.; Pazos, L. M.; Credgington, D.; Hanusch, F.; Bein, T.; Snaith, H. J.; Friend, R. H. Bright LightEmitting Diodes Based on Organometal Halide Perovskite. Nat. Nanotechnol. 2014, 9, 687-692.

(7) Brenner, P.; Bar-On, O.; Jakoby, M.; Allegro, I.; Richards, B. S.; Paetzold, U. W.; Howard, I. A.; Scheuer, J.; Lemmer, U. Continuous Wave Amplified Spontaneous Emission in Phase-Stable Lead Halide Perovskites. Nat. Commun. 2019, 10, No. 988.

(8) Zhu, H. M.; Fu, Y. P.; Meng, F.; Wu, X. X.; Gong, Z. Z.; Ding, Q.; Gustafsson, M. V.; Trinh, M. T.; Jin, S.; Zhu, X. Y. Lead Halide Perovskite Nanowire Lasers with Low Lasing Thresholds and High Quality Factors. Nat. Mater. 2015, 14, 636-642.

(9) Utzat, H.; Sun, W. W.; Kaplan, A. E. K.; Krieg, F.; Ginterseder, M.; Spokoyny, B.; Klein, N. D.; Shulenberger, K. E.; Perkinson, C. F.; Kovalenko, M. V.; Bawendi, M. G. Coherent Single-Photon Emission from Colloidal Lead Halide Perovskite Quantum Dots. Science 2019, 363, 1068-1072.

(10) Luo, J. J.; Wang, X. M.; Li, S. R.; Liu, J.; Guo, Y. M.; Niu, G. D.; Yao, L.; Fu, Y. H.; Gao, L.; Dong, Q. S.; Zhao, C. Y.; Leng, M. Y.; Ma, F. S.; Liang, W. X.; Wang, L. D.; Jin, S. Y.; Han, J. B.; Zhang, L. J.; Etheridge, J.; Wang, J. B.; Yan, Y. F.; Sargent, E. H.; Tang, J. Efficient and Stable Emission of Warm-White Light from Lead-Free Halide Double Perovskites. Nature 2018, 563, 541-545.

(11) Chen, Q. S.; Wu, J.; Ou, X. Y.; Huang, B. L.; Almutlaq, J.; Zhumekenov, A. A.; Guan, X. W.; Han, S. Y.; Liang, L. L.; Yi, Z. G.; Li, J.; Xie, X. J.; Wang, Y.; Li, Y.; Fan, D. Y.; Teh, D. B. L.; All, A. H.; Mohammed, O. F.; Bakr, O. M.; Wu, T.; Bettinelli, M.; Yang, H. H.; Huang, W.; Liu, X. G. All-Inorganic Perovskite Nanocrystal Scintillators. Nature 2018, 561, 88-93.

(12) Yakunin, S.; Benin, B. M.; Shynkarenko, Y.; Nazarenko, O.; Bodnarchuk, M. I.; Dirin, D. N.; Hofer, C.; Cattaneo, S.; Kovalenko, M. V. High-Resolution Remote Thermometry and Thermography Using Luminescent Low-Dimensional Tin-Halide Perovskites. Nat. Mater. 2019, 18, 846-852.

(13) Meinardi, F.; Akkerrman, Q. A.; Bruni, F.; Park, S.; Mauri, M.; Dang, Z. Y.; Manna, L.; Brovelli, S. Doped Halide Perovskite Nanocrystals for Reabsorption-Free Luminescent Solar Concentrators. ACS Energy Lett. 2017, 2, 2368-2377.

(14) Milstein, T. J.; Kroupa, D. M.; Gamelin, D. R. Picosecond Quantum Cutting Generates Photoluminescence Quantum Yields Over $100 \%$ in Ytterbium-Doped $\mathrm{CsPbCl} 3$ Nanocrystals. Nano Lett. 2018, 18, 3792-3799.

(15) Pazos-Outon, L. M.; Szumilo, M.; Lamboll, R.; Richter, J. M.; Crespo-Quesada, M.; Abdi-Jalebi, M.; Beeson, H. J.; Vrucinic, M.; Alsari, M.; Snaith, H. J.; Ehrler, B.; Friend, R. H.; Deschler, F. Photon Recycling in Lead Iodide Perovskite Solar Cells. Science 2016, 351, $1430-1433$.

(16) Hoye, R. L. Z.; Eyre, L.; Wei, F. X.; Brivio, F.; Sadhanala, A.; Sun, S. J.; Li, W. W.; Zhang, K. H. L.; MacManus-Driscoll, J. L.; Bristowe, P. D.; Friend, R. H.; Cheetham, A. K.; Deschler, F. Fundamental Carrier Lifetime Exceeding $1 \mu \mathrm{s}$ in $\mathrm{Cs}_{2} \mathrm{AgBiBr}_{6}$ Double Perovskite. Adv. Mater. Interfaces 2018, 5, No. 1800464.

(17) Kovalenko, M. V.; Protesescu, L.; Bodnarchuk, M. I. Properties and Potential Optoelectronic Applications of Lead Halide Perovskite Nanocrystals. Science 2017, 358, 745-750. 
(18) Smith, M. D.; Connor, B. A.; Karunadasa, H. I. Tuning the Luminescence of Layered Halide Perovskites. Chem. Rev. 2019, 119, 3104-3139.

(19) Mao, L. L.; Guo, P. J.; Kepenekian, M.; Hadar, I.; Katan, C.; Even, J.; Schaller, R. D.; Stoumpos, C. C.; Kanatzidis, M. G. Structural Diversity in White-Light-Emitting Hybrid Lead Bromide Perovskites. J. Am. Chem. Soc. 2018, 140, 13078-13088.

(20) Romanov, A. N.; Haula, E. V.; Kouznetsov, M. S.; Lisitsky, I. S.; Pimkin, N. A.; Boldyrev, K. N.; Sereda, A. E.; Shashkin, D. P.; Korchak, V. N. Preparation of Optical Media with NIR Luminescent $\mathrm{Bi}^{+}$Impurity Centers by Ion Exchange. J. Am. Ceram. Soc. 2019, 102, 2745-2751.

(21) Vandersteen, A. C.; Dirksen, G. J. Luminescence and CrystalGrowth of $\mathrm{Cs}_{2} \mathrm{NaYCl}_{6}$-Bi. Chem. Phys. Lett. 1978, 59, 110-112.

(22) Nikl, M.; Mihokova, E.; Nitsch, K. Photoluminescence and Decay Kinetics of $\mathrm{Cs}_{4} \mathrm{PbCl}_{6}$ Single-Crystals. Solid State Commun. 1992, 84, 1089-1092.

(23) Morad, V.; Shynkarenko, Y.; Yakunin, S.; Brumberg, A.; Schaller, R. D.; Kovalenko, M. V. Disphenoidal Zero-Dimensional Lead, Tin, and Germanium Halides: Highly Emissive Singlet and Triplet Self-Trapped Excitons and X-ray Scintillation. J. Am. Chem. Soc. 2019, 141, 9764-9768.

(24) Zhou, C. K.; Worku, M.; Neu, J.; Lin, H. R.; Tian, Y.; Lee, S. J.; Zhou, Y.; Han, D.; Chen, S. Y.; Hao, A.; Djurovich, P. I.; Siegrist, T.; $\mathrm{Du}$, M. H.; Ma, B. W. Facile Preparation of Light Emitting Organic Metal Halide Crystals with Near-Unity Quantum Efficiency. Chem. Mater. 2018, 30, 2374-2378.

(25) Li, Z. Y.; Li, Y.; Liang, P.; Zhou, T. L.; Wang, L.; Xie, R. J. Dual-Band Luminescent Lead-Free Antimony Chloride Halides with Near-Unity Photoluminescence Quantum Efficiency. Chem. Mater. 2019, 31, 9363-9371.

(26) Sedakova, T. V.; Mirochnik, A. G.; Karasev, V. E. Structure and Luminescence Properties of Antimony(III) Complex Compounds. Opt. Spectrosc. 2008, 105, 517-523.

(27) Zhou, C. K.; Lin, H. R.; Tian, Y.; Yuan, Z.; Clark, R.; Chen, B. H.; van de Burgt, L. J.; Wang, J. C.; Zhou, Y.; Hanson, K.; Meisner, Q. J.; Neu, J.; Besara, T.; Siegrist, T.; Lambers, E.; Djurovich, P.; Ma, B. W. Luminescent Zero-Dimensional Organic Metal Halide Hybrids with Near-Unity Quantum Efficiency. Chem. Sci. 2018, 9, 586-593.

(28) McCall, K. M.; Friedrich, D.; Chica, D. G.; Cai, W. Z.; Stoumpos, C. C.; Alexander, G. C. B.; Deemyad, S.; Wessels, B. W.; Kanatzidis, M. G. Perovskites with a Twist: Strong $\operatorname{In}^{1+}$ Off-Centering in the Mixed-Valent $\operatorname{CsInX}_{3}(\mathrm{X}=\mathrm{Cl}, \mathrm{Br})$. Chem. Mater. 2019, 31, 9554-9566.

(29) Oomen, E. W. J. L.; Smit, W. M. A.; Blasse, G. The Luminescence of $\mathrm{Cs}_{2} \mathrm{NaSbCl}_{6}$ and $\mathrm{Cs}_{2} \mathrm{NaSbBr}_{6}$ - a Transition from a Localized to a Delocalized Excited-State. Chem. Phys. Lett. 1987, 138, $23-28$.

(30) Jacobs, P. W. M. Alkali-Halide Crystals Containing Impurity Ions with the $\mathrm{ns}^{2}$ Ground-State Electronic Configuration. J. Phys. Chem. Solids 1991, 52, 35-67.

(31) Jing, Y. Y.; Liu, Y.; Zhao, J.; Xia, Z. G. $\mathrm{Sb}^{3+}$ Doping-Induced Triplet Self-Trapped Excitons Emission in Lead-Free $\mathrm{Cs}_{2} \mathrm{SnCl}_{6}$ Nanocrystals. J. Phys. Chem. Lett. 2019, 10, 7439-7444.

(32) Volonakis, G.; Filip, M. R.; Haghighirad, A. A.; Sakai, N.; Wenger, B.; Snaith, H. J.; Giustino, F. Lead-Free Halide Double Perovskites via Heterovalent Substitution of Noble Metals. J. Phys. Chem. Lett. 2016, 7, 1254-1259.

(33) Meng, W. W.; Wang, X. M.; Xiao, Z. W.; Wang, J. B.; Mitzi, D. B.; Yan, Y. F. Parity-Forbidden Transitions and Their Impact on the Optical Absorption Properties of Lead-Free Metal Halide Perovskites and Double Perovskites. J. Phys. Chem. Lett. 2017, 8, 2999-3007.

(34) Oomen, E. W. J. L.; Dirksen, G. J. Crystal-Growth and Luminescence of $\mathrm{Sb}^{3+}$-Doped $\mathrm{Cs}_{2} \mathrm{NaScCl}_{6}, \mathrm{Cs}_{2} \mathrm{NaYCl}_{6}, \mathrm{Cs}_{2} \mathrm{NaLaCl}_{6}$. Mater. Res. 1985, 20, 453-457.

(35) Oomen, E. W. J. L.; Dirksen, G. J.; Smit, W. M. A.; Blasse, G. On the Luminescence of the $\mathrm{Sb}^{3+}$ Ion in $\mathrm{Cs}_{2} \mathrm{NaScBr}_{6}, \mathrm{Cs}_{2} \mathrm{NaYBr}_{6}$, $\mathrm{Cs}_{2} \mathrm{NaLaBr}_{6}$. J. Phys. C: Solid State Phys. 1987, 20, 1161-1171.
(36) Zeng, R.; Zhang, L.; Xue, Y.; Ke, B.; Zhao, Z.; Huang, D.; Wei, Q.; Zhou, W.; Zou, B. Highly Efficient Blue Emission from SelfTrapped Excitons in Stable $\mathrm{Sb}^{3+}$-Doped $\mathrm{Cs}_{2} \mathrm{NaInCl}_{6}$ Double Perovskites. J. Phys. Chem. Lett. 2020, 11, 2053-2061.

(37) Shannon, R. D. Revised Effective Ionic-Radii and Systematic Studies of Interatomic Distances in Halides and Chalcogenides. Acta Crystallogr., Sect. A 1976, 32, 751-767.

(38) Morss, L. R.; Siegal, M.; Stenger, L.; Edelstein, N. Preparation of Cubic Chloro Complex Compounds of Trivalent Metals $\mathrm{Cs}_{2} \mathrm{NaMCl}_{6}$. Inorg. Chem. 1970, 9, 1771-1775.

(39) Toby, B. H.; Von Dreele, R. B. GSAS-II: the Genesis of a Modern Open-Source All Purpose Crystallography Software Package. J. Appl. Crystallogr. 2013, 46, 544-549.

(40) Retuerto, M.; Emge, T.; Hadermann, J.; Stephens, P. W.; Li, M. R.; Yin, Z. P.; Croft, M.; Ignatov, A.; Zhang, S. J.; Yuan, Z.; Jin, C.; Simonson, J. W.; Aronson, M. C.; Pan, A.; Basov, D. N.; Kotliar, G.; Greenblatt, M. Synthesis and Properties of Charge-Ordered Thallium Halide Perovskites, $\mathrm{CsTl}_{0.5}{ }^{+} \mathrm{Tl}_{0.5}{ }^{3+} \mathrm{X}_{3}(\mathrm{X}=\mathrm{F}$ or $\mathrm{Cl})$ : Theoretical Precursors for Superconductivity? Chem. Mater. 2013, 25, 40714079.

(41) Guedira, T.; Wignacourt, J. P.; Drache, M.; Lorriauxrubbens, A.; Wallart, F. Phase-Transition in a Chloro-Elpasolite, $\mathrm{Cs}_{2} \mathrm{KInCl}_{6}$. Phase Transitions 1988, 13, 81-85.

(42) Benachenhou, F.; Mairesse, G.; Nowogrocki, G.; Thomas, D. Structural Studies of Cs-K-Bi Mixed Chlorides Relation to the Crystal-Structures of $\mathrm{A}_{2} \mathrm{BMX}_{6}, \mathrm{~A}_{3} \mathrm{MX}_{6}$, and $\mathrm{A}_{2} \mathrm{MX}_{6}$. J. Solid State Chem. 1986, 65, 13-26.

(43) Reisfeld, R.; Boehm, L.; Barnett, B. Luminescence and Nonradiative Relaxation of $\mathrm{Pb}^{2+}, \mathrm{Sn}^{2+}, \mathrm{Sb}^{3+}$, and $\mathrm{Bi} 3+$ in Oxide Glasses. J. Solid State Chem. 1975, 15, 140-150.

(44) Rudin, S.; Reinecke, T. L. Effects of Exciton-Acoustic-Phonon Scattering on Optical Line Shapes and Exciton Dephasing in Semiconductors and Semiconductor Quantum Wells. Phys. Rev. B 2002, 66, No. 085314.

(45) Sheldrick, G. M. Crystal Structure Refinement with SHELXL. Acta Crystallogr., Sect. C: Struct. Chem. 2015, 71, 3-8.

(46) Dolomanov, O. V.; Bourhis, L. J.; Gildea, R. J.; Howard, J. A. K.; Puschmann, H. OLEX2: a Complete Structure Solution, Refinement and Analysis Program. J. Appl. Crystallogr. 2009, 42, 339-341.

(47) Blochl, P. E. The Projector-Augmented Wave (PAW) Method and Dynamical Properties of Organometallic Compounds. Abstr. Pap. Am. Chem. Soc. 1995, 209, 115.

(48) Kresse, G.; Joubert, D. From Ultrasoft Pseudopotentials to the Projector Augmented-Wave Method. Phys. Rev. B 1999, 59, 17581775.

(49) Perdew, J. P.; Burke, K.; Ernzerhof, M. Generalized Gradient Approximation Made Simple. Phys. Rev. Lett. 1997, 78, 1396.

(50) $\mathrm{Du}, \mathrm{M}$. H. Density Functional Calculations of Native Defects in CH3NH3PbI3: Effects of Spin-Orbit Coupling and Self-Interaction Error. J. Phys. Chem. Lett. 2018, 9, 3799.

(51) Bradley, C. J.; Cracknell, A. P. The Mathematical Theory of Symmetry in Solids; Representation Theory for Point Groups and Space Groups; Clarendon Press: Oxford, 1972; p xii, 745 p. 